\title{
(Life) Science Funding in Switzerland (2)
}

\author{
Mauro Dell'Ambrogio*
}

\begin{abstract}
In comparison with other European countries, Switzerland is very well positioned in terms of research funding and output thanks to a large part to the approx. 7 billion CHF annually with which the Swiss Federal Government funds education, research and innovation.
\end{abstract}

Keywords: Science funding · Switzerland

\section{Switzerland and EU Funding}

The Federal Government of Switzerland funds education, research and innovation with around 7 billion CHF annually. Of this annual budget, 2.5 billion are allocated to the Federal Institutes of Technology (ETH Zurich/EPF Lausanne) and the four research facilities of the ETH domain (Paul Scherrer Institute (PSI), Swiss Federal Institute for Forest, Snow and Landscape Research (WSL), Swiss Institute for Materials Science and Technology (EMPA), and Swiss Federal Institute of Aquatic Research and Technology (EAWAG)) and 1.3 billion to the cantonal Universities and Universities of Applied Sciences. In addition, research is explicitly funded on a competitive basis via the Swiss National Science Foundation (SNSF, 0.9 billion CHF) and the Swiss Commission for Technology and Innovation (CTI, 0.2 billion $\mathrm{CHF}$ ). Finally, about a third of the resources ( 0.5 billion $\mathrm{CHF}$ ) for competitive funding is allocated to the European Framework Programmes (FPs), which entitle Swiss researchers to access EU funding. The Swiss involvement in the European Framework Programs has been very successful and has increased steadily from 1992 (FP 3: 500 Swiss project participants) to 2014 (FP 7: 4300 participants).

\footnotetext{
${ }^{\star}$ Dr. iur. M. Dell'Ambrogio
}

State Secretary for Education, Research and Innovation

Staatssekretariat für Bildung, Forschung und Innovation SBFI

Einsteinstrasse 2, CH-3003 Bern

Contact: Martin Fischer, Head of Communication, SBFI

E-mail: martin.fischer@sbfi.admin.ch

\$Transcript of the conference recorded at the LS2 Annual Meeting 2016, 16.2.2016, edited by LS2

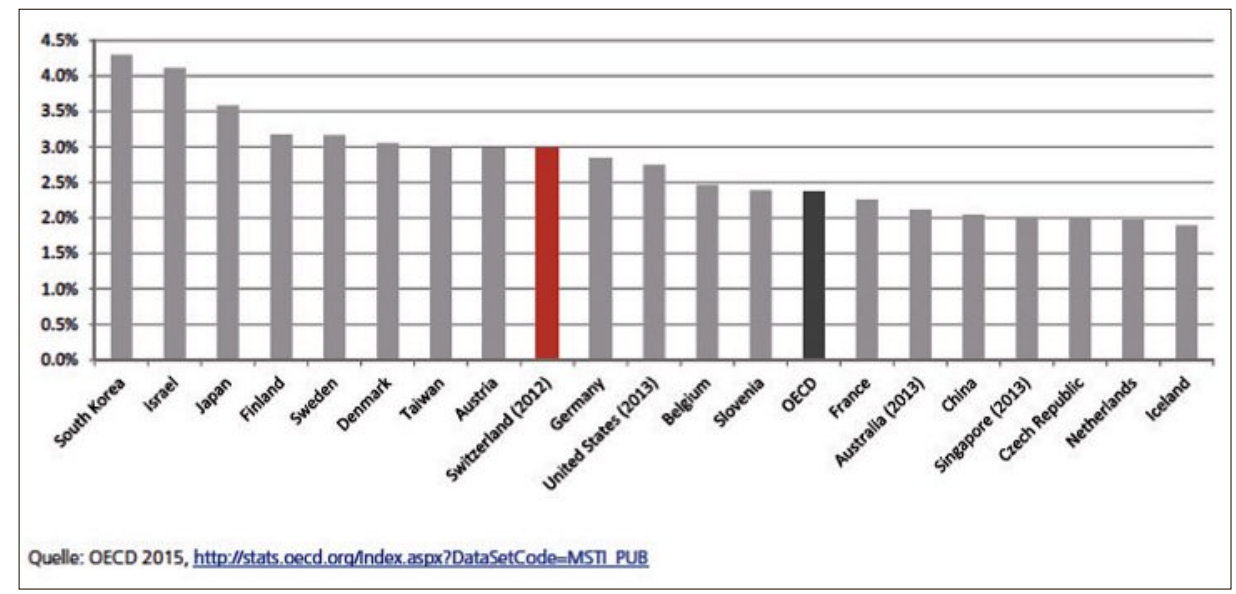

Fig. 1. Expenditure (\%) of Gross Domestic Product on Research and Development.

In comparison with other European countries, Switzerland is very well positioned not only in terms of research funding (Switzerland spends 3\% of the GDP on research and development, Fig. 1), but also in terms of output. Indeed, Switzerland ranks first in number of publications/ inhabitant over the 2009-2013 period (Fig. 2 ), which is an indicator of the quality of Swiss research.

One of the key issues is who benefits most from the funds of the EU framework programs. The largest amount of these funds

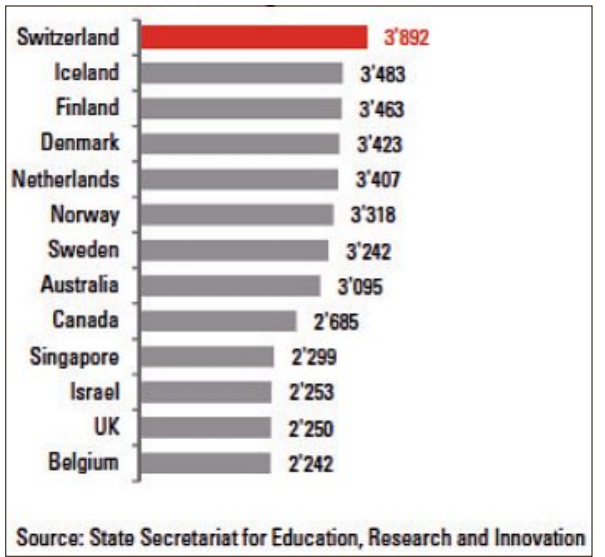

Fig. 2. Number of publications per million inhabitants in the period 2009-2013.
$(40 \%)$ is distributed to the institutions of the ETH domain, followed by Universities and small-to-medium size companies. In contrast to the SNF(focused on independent and 'non-for profit' research funding), the European framework programs also supports research conducted in the private sector notably for innovation. Thus, the Swiss economy benefits directly from EU funding.

\section{How is the EU funding distributed?}

One third of all funds are allocated to individual competitive grants from the European Research Council (ERC) and the Marie-Slkodowska-Curie (MSC) program, whereas two thirds of the funds are invested in competitive research consortia, composed of scientists from at least three different countries. These consortia are driven top-down with clearly set topics and goals, and aim at supporting the cooperation between universities. However, with the vote against mass immigration by the Swiss population in 2014, Switzerland has lost its status of fully associated country, for a partially associated status. As a consequence, Switzerland-based scientists are still allowed to participate in consortia, 
but the funding is not supported by the EU but by the Swiss government. For individual grants (support of excellence in research), Switzerland remains an associated country with all rights.

The uncertainty about the association status of Switzerland concerning EU funding also represents a challenge in terms of budgeting. Today, if Swiss researchers participate in a call, the funds will have to be invested for a two-to-three year period in the future. But, it is difficult to predict whether the status of fully associated country can and will be restored, and how much of the budget should be invested for the EU consortia research. Therefore, there is an element of risk for Swiss researchers, but also for other countries to cooperate with Swiss researchers (also psychologically speaking). Recent analysis already reveals that the participation of Swiss-based researchers has been reduced by nearly $50 \%$ in the consortia program, resulting in a net loss of scientific cooperation (since Horizon 2020 was only launched recently and only limited data is available as of yet, the financial consequences and above all the scientific impact of these developments are currently still difficult to assess).

Even with reduced participation, Switzerland seems to maintain its success rate, particularly in the ERC funding program. After correction for the size of the countries, Swiss-based researchers are five times more successful than Germanybased researchers. The financial issues are also rather negligible: the statistical analysis of the EU FP 7 reveals that the return of investment was in total $123 \%$ in Euro $(110 \%$ in CHF, due to the devaluation of the Euro). After deduction of the administrative costs, the return is between $10-15 \%$ for the researcher.

A key issue is that $85 \%$ of Swissbased applicants for ERC grants are not Swiss citizens. Hence, the success of Swiss research is based to a large extent on the fact that Switzerland is very good in attracting excellent scientists from all over the world. To evaluate what could be the consequences of complete dissociation of Switzerland from the EU funding schemes, we can draw a parallel with European football. European football thrives because of exchange and transfer of players, there would be no progress if players stayed in their home club for their entire careers. Should Switzerland be excluded from the EU funding schemes, the most decisive element would be the loss of scientific cooperation, hence the loss of bilateral relations and of the attractiveness of Switzerland as a research place for a large number of scientists.

\section{Science Policy in Switzerland}

In Switzerland, the majority of funding for Research and Development $(\mathrm{R}+\mathrm{D})$, i.e. from basic research to product development, comes from the private sector (see Table 1), such as the pharmaceutical industry. Switzerland is therefore in an exceptional position, when compared to other countries where research is mainly funded by the government.

While the federal research funding amounts to almost 3 billion $\mathrm{CHF}$ and the canton research funding to almost 2 billion $\mathrm{CHF}$, more than 11 billion $\mathrm{CHF}$ come from the private sector. Additionally, Swiss companies invest a large amount of money in the $\mathrm{R}+\mathrm{D}$ sector abroad. Globally speaking, a reduction of $5 \%$ of the federal budget dedicated to competitive research funding (SNF or CTI) is rather irrelevant for $\mathrm{R}+\mathrm{D}$ financing, when compared to the impact that could result from the decision of big Swiss companies to move their research and production sites. The rules and regulations set out by the ministry of health and environment concerning experimentation on humans, environment, GMOs etc. has to be set out carefully to balance the interests of big companies and citizens. A wrong decision in this domain could have a huge impact on $\mathrm{R}+\mathrm{D}$ in Switzerland, to a much larger extent than a change in the budget of federal research funding.

One funding instrument that has been rarely used in the Life Sciences but is becoming increasingly important is the CTI (Commission of Technology and Innovation). The Swiss Parliament decided to transform the CTI into an independent agency named Innosuisse, with the goal to increase its performance. The idea is to better intertwine basic and applied science (and thus the CTI and SNF), which is one of the prevailing strategic developments of the Swiss Government. The main advantage for restructuration of the CTI, and for its transformation into Innosuisse is an increased autonomy in developing and implementing funding tools (like the SNF); until now, all CTI instruments have been decided by law (through Parliament). Another advantage is that Innosuisse will be more competitive internationally and will entice more international cooperation. Traditionally, the CTI focussed mainly on Swiss-based companies and funding with the goal to create jobs in Switzerland, as well as to fund Swiss projects and to prefer Swiss over international applications. The world has changed and a focus on Switzerland alone has become too narrow.

One of the major flagships of science funding in Switzerland is to reduce the gap between basic and applied science and to better 'escort' a product from the first lab experiments to its development and application. However, this raises new questions, such as intellectual property, which will need to be solved in the future.

\section{The difficulty is how to judge innovation or innovative potential}

The Swiss CTI handles a budget, which is fivefold smaller than that of the SNF. In other countries, such as Finland, the expenditure for the innovation agencies is five times higher, although this situation is about to change after the NOKIA crisis with more funding allocated to basic research in the future. If a relatively small part of federal funds is allocated to innovation in Switzerland, a new policy to support innovation will be implemented. This new policy is a consequence of the good conditions for innovation and entrepreneurship in Switzerland, which include good infrastructure, social peace, a low job market regulation and good education and basic science. Hence, the high potential of Swiss innovation is

Table 1. Research and Development funding of the different sectors, from private to the government (federal and cantonal), private organisations and from abroad.

\begin{tabular}{|l|c|c|}
\hline R+D funding (2012) & CHF (Mio) & \% \\
\hline Private industry & 11250 & $60.8 \%$ \\
\hline State & 4705 & $25.4 \%$ \\
\hline \multicolumn{1}{|c|}{ Federal } & 2835 & $15.3 \%$ \\
\hline$\quad$ Cantonal & 1870 & $10.1 \%$ \\
\hline $\begin{array}{l}\text { Private not-for-profit } \\
\text { organisations and others }\end{array}$ & 320 & $1.7 \%$ \\
\hline International & 2235 & $12.1 \%$ \\
\hline Total & 18510 & $100 \%$ \\
\hline
\end{tabular}


largely independent of the small funding tools of the CTI, whereas other countries invest a lot more in innovation. The goal in Switzerland is to try and connect traditional (basic) research funding better with innovation while avoiding a shift in funds.

\section{International Collaborations}

Finally, Switzerland has strong international collaborations in research, in part via the efforts of the Federal Government, for example in supporting research programs such as the EU FP or a few joint projects with other countries such as India or China. Furthermore, international cooperation in education, while steered at a political level, is always initiated by the personal contact of researchers or organisations. Finally, the Swiss government has established a worldwide network for Swiss researchers who work in a foreign country: Swissnex. The goal of Swissnex is to foster collaborations, and to represent the interests of Swiss researchers abroad.

Received: August 18, 2016 